\title{
An Overview and Recent Advances in Fuzzy ARTMAP Classifier Usage for Mapping Purposes Using Remotely Sensed Data
}

\author{
P. F. Prado ${ }^{1 *}$ and I. C. S. Duarte ${ }^{2}$ \\ ${ }^{1}$ Department of Earth Physics and Thermodynamics, University of Valencia, Valencia, Valencian Community 50 46100, Spain \\ ${ }^{2}$ Department of Biology, Federal University of São Carlos, Sorocaba, São Paulo 18052-780, Brazil
}

Received 18 April 2020; revised 08 June 2020; accepted 15 June 2020; published online 30 June 2020

\begin{abstract}
This paper presents an overview and recent advances on the usage of Fuzzy ARTMAP artificial neural network architecture (and its variants) for mapping purposes using remotely sensed data. It aims to offer a perspective into the past and ongoing developments of this specific research field. Moreover, this paper suggests initial pathways for those who intend to perform a scientific investigation using this artificial neural network architecture. Some applications of this architecture in other research fields are highlighted for general knowledge purposes, as well as suggestions of code repositories to implement it. Possible gaps in the literature related to Fuzzy ARTMAP classifier usage for mapping are suggested, leading to paths for future developments in this field of research.
\end{abstract}

Keywords: images, land cover, land use, mapping, machine learning, neuro-fuzzy, sensors

\section{Introduction}

An Artificial Neural Network (ANN) is a computational approach that aims to mimic and simulate the biological nervous system that has parallel features. It also has the ability to manipulate incomplete or diffuse information and noisy data, and consequently it is considered fault tolerant. An ANN is an important tool in spatial data processing and analysis (Gopal, 2016), but scalability and availability of labelled training data are considered problems for some ANN applications. Currently, complementing process-based approaches (Eslami et al., 2017), data-oriented approach (ANN) applications are diverse and widespread among many fields in the natural sciences, in applications related to soil and water study (Ferreira et al., 2010; Dehghani et al., 2017; Rastegaripour et al., 2019).

This also extends to modelling approaches oriented by Fuzzy logic (Aliabad et al., 2019b). When considered together (ANN and Fuzzy logic), the potential of fusion called the NeuroFuzzy approach stands out that encompasses Fuzzy ART-MAP (FAM) architecture (Carpenter et al., 1992).

Mas and Flores (2008) presented a review of the ANN approach to analyze remotely sensed data. In this paper, the artificial neuron model and some ANN architectures are detailed, such as single-layer feedforward networks and multilayer feedforward networks. Concepts such as the activation function and its typical role in defining neuron outputs are described.

${ }^{*}$ Corresponding author. fax: +551532297543 .

E-mail address: piefedo@alumni.uv.es (P. F. Prado).

ISSN: 2663-6859 print/2663-6867 online

(C) 2020 ISEIS All rights reserved. doi:10.3808/jeil.202000032.
Single-layer perceptron and multilayer-perceptron classes are discussed, as is the backpropagation algorithm. The ANN class; called Radial Basis Functions (RBFs); is also considered in this article. Self-organizing maps (SOM) and their links to competitive learning are addressed.

Recurrent networks, which are related to the Adaptive Resonance Theory (ART) (Carpenter et al., 1991) are addressed concerning some of its theoretical aspects and remote sensing applications.

Some considerations regarding sensors and dataset characteristics are described in this paper. In addition, the typical data pre-processing steps were also presented in this work. Cases related to pixel unmixing and retrieving biophysics parameters, as well as land cover classification are shown. Among the articles analyzed, these authors highlighted a list of studies related to the FAM that were available in 2008. The authors point out properties linked to cross-validation, dynamic learning and the possibility of mapping the activation layer as positive characteristics of neural networks related to ART (Carpenter et al., 1991), which deals with the stability-plasticity dilemma and underlies the FAM proposition (Carpenter et al., 1992).

Gopal (2016) states that concerning the equivalent graph (i.e., mathematical) representation, the FAM is considered as a recurrent network, i.e. its architecture relates to cyclic graphs, which are frequently complex and hard to assess in contrast to the class called feedforward ANN that would allow the easiest interpretation by an expert.

In their book entitled "Classification methods for remotely sensed data", Mather and Tso (2016) devote one section to ANNs focusing on the multilayer perceptron, Kohonen SOM, 


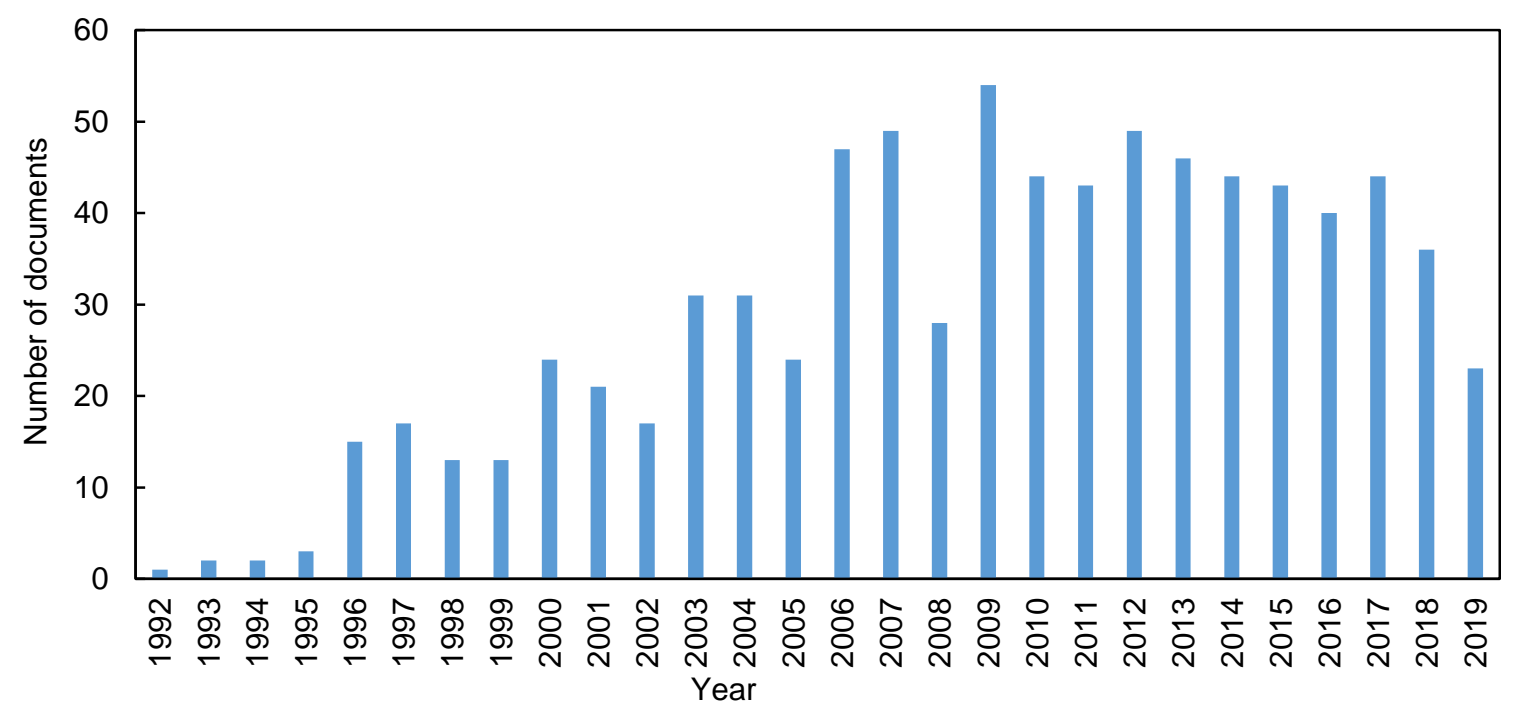

Figure 1. Number of documents retrieved on a yearly basis from 1992 to 2019.

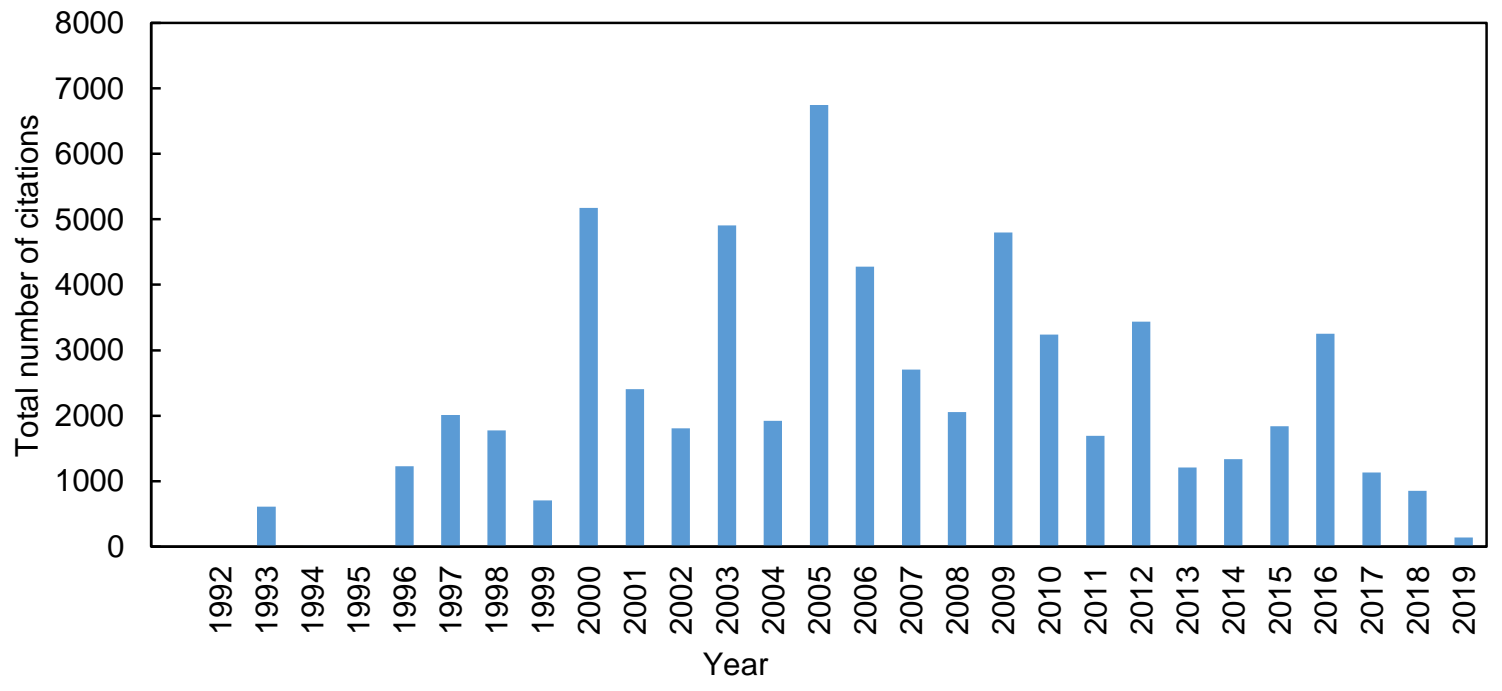

Figure 2. Total number of citations of documents retrieved every year from 1992 to 2019.

counter-propagation networks, Hopfield networks and include a discussion about FAM as part of a topic related to ART.

Salah et al. (2017) following the same line as Mas, Mather and Tso present an investigation focused on the classification of remote sensed data. An interesting taxonomy scheme of this field is presented. Salah also discusses FAM features such as its five key parameters and its possible numerical ranges including, in this approach, its typical values.

Bibliometric records related to the topic covered in this paper were obtained from the freely accessible Google Scholar data source and its search engine. This search engine was used to discover the temporal dynamics of document production considering the aim of this research and its citations. We carried out a bibliometric analysis using the following keywords "classifier Fuzzy ART-MAP use mapping purposes using remotely sensed data" in order to be restricted to the title of this article (Harzing, 2007).

This research was adjusted for recovering data from 1992 (the year that the FAM proposition was coincidentally published) up to 2019 as it is the last complete year so far. The number of documents and the summation of citations of these retrieved documents were then graphically summarized on a yearly basis (Figures 1 and 2).

Škrjanc et al. (2019) and Webster et al. (2020) studied evolving Neuro-Fuzzy architectures that partially relate to the evoked stability-plasticity features of the FAM using online learning capacity i.e. to adapt, in response to exposure to previously unknown data, if necessary in the classification task.

The FAM architecture could be framed as an incremental classifier, but not as an intelligent classifier that evolves (Škr- 
janc et al., 2019), because the FAM structure would depend on previous choices and the classifier that evolves would selfdevelop its structure over time based on basic conditions.

Furthermore, a list of previous scientific research with partially related objectives can be found in Silva et al. (2019) and the references. This paper is included in a special issue in honor of the $80^{\text {th }}$ anniversary of one of the most authors of the FAM concept, Stephen Grossberg, published by the Neural Net-works journal.

\section{Development: Initial FAM Presence in the Literature and Selected Papers}

The documents selected and covered in this section are listed (Table 1) to provide the reader with a glimpse, including information about their citations according to the Google Scholar database. Carpenter et al. (1991) presented the Fuzzy ART model extending learning based on binary inputs from the Adaptive Resonance Theory (ART-1) to learning from analog inputs. This extension was based on using the $\mathrm{MIN}\left({ }^{\wedge}\right)$ operator of the Fuzzy set theory as a substitute for the set theory intersection operation. According to the authors and signaling the next step that consolidates FAM, the ART Fuzzy model could be incorporated into supervised learning systems to map mdimensional vectors to $n$-dimensional vectors in the context of an architecture called Fuzzy ARTMAP.

The generalization of the ARTMAP network called Fuzzy ARTMAP (FAM) architecture was then detailed in a specific article for these purposes by Carpenter et al. (1992). In this original proposal, FAM was described as having a voting strategy, based on the ARTMAP architecture, which would relate its prediction to the result of the largest number of simulations avoiding ordering effects regarding the presentation of inputs during the training phase. A confidence estimate could be attributed to these competing predictions due to the characteristics of this voting strategy, which can be useful for one handling noisy, small or incomplete training datasets.

As part of a special issue entitled "On Non-conventional Pattern Analysis in Remote Sensing" by Pattern Recognition Letters journal (Binaghi et al., 1996), Blonda et al. (1996) discussed integrating the potentialities of neural networks with those of Fuzzy logic.

The FAM was listed by these authors as one option in this context. Gopal and Fischer (1996) analyzed and compared 3 different classifiers plus the Maximum Likelihood Classifier (MLC) using data generated by LANDSAT-5. These authors reported that FAM performed the best in this comparative study.

Carpenter et al. (1997) compared FAM with other classifiers in the mapping vegetation task. These classifiers are the core of a systematic approach for using multispectral and ancillary data to perform the automatic classification of vegetation land cover at the species level. According to this report, FAM performed better in terms of accuracy: The MLC, Knearest neighborhood (K-NN), and ANN trained with the backpropagation learning algorithm. This work corroborated previous work by Gopal and Fischer (1996).
Continuing along these lines, Gopal et al. (1999) studied the FAM architecture for the global Land cover Classification task. The data of input that they used were the annual sequence of 12 monthly normalized difference vegetation index (NDVI) values and altitude.

The NDVI data were related to the products of the operation of the Advanced Very-High-Resolution Radiometer (AVHRR) sensor at a resolution of $1^{\circ}$ by $1^{\circ}$. The output vector of data comprised 12 categories of vegetation signalized on a presence/absence approach ( 1 or 0). A total of 2719 pixels were used for training, 679 for a test, making a total of 3398 pixels. Eleven land cover classes and 3 FAM setups were tested against MLC. The authors concluded that the FAM performed better than the MLC. The FAM's accuracy in classifying the test dataset was $85 \%$ versus $78 \%$ obtained using the MLC classifier. They also pointed out that compared to MLC the FAM classifier does not show an improved performance as a consequence of the increase in the size of the training dataset. This paper suggests that FAM is a suitable classifier for land cover classification projects on a global scale, showing advantages of this architecture such as the voting strategy analysis as a source of additional information regarding errors for end-users of a produced map following this approach.

Liu et al. (2001) proposed a system called ART-VIP (ART for Visualization and Image Processing) that aimed to incorporate FAM into image processing software (public domain) that would be user friendly to acquire knowledge about the principles and dynamics of FAM functioning (supported by scientific visualization tools) while performing the land cover classification task. This system was inserted into the context of mapping the land cover of North America using MODIS imagery.

Since proposing FAM, some of the problems of this architecture have been addressed and some suggestions for improvement have been proposed, as can be seen in Parsons and Carpenter (2003); these authors proposed FAM variants. As a result of testing all the variants of FAM by classifying a single set of data for testing, these authors presented the following increasing order according to the accuracy of the classifications:

FAM $\subset$ default ARTMAP $\subset$ ARTMAP-IC $\subset$ distributed ARTMAP

Parsons and Carpenter (2003) use the aerial optical image of the Monterrey Naval postgraduate school (USA) (1.5 million pixels) for map production and the following clustering categories for the evaluated pixels: roofs, roads, footpaths, grass, trees, among others. It can be stated that the default ARTMAP variant can be recommended as an initial choice among the other evaluated variants. Liu et al. (2004) relied on FAM and the decision tree as the components of a hybrid approach to evaluate uncertainty and confidence in land cover classification. These classifiers were similar in $68 \%$ of the pixel classifications representative of North American land cover.

FAM achieved an accuracy of $59 \%$ and $60 \%$ without and 
Table 1. List of Document Titles, Year of Publication and Citations According to the Google Scholar Dataset

\begin{tabular}{|c|c|c|c|c|c|}
\hline$\#$ & Authors & Year & Title & Cited by & Journal/ Book \\
\hline 1 & Carpenter et al. & 1991 & $\begin{array}{l}\text { Fuzzy ART: Fast stable learning and } \\
\text { categorization of analog patterns by an adaptive } \\
\text { resonance system }\end{array}$ & 2193 & Neural Networks \\
\hline 2 & Carpenter et al. & 1992 & $\begin{array}{l}\text { A neural network architecture for incremental } \\
\text { supervised learning of analog multidimensional } \\
\text { maps }\end{array}$ & 2581 & IEEE Transactions on Neural Networks \\
\hline 3 & $\begin{array}{l}\text { Gopal and } \\
\text { Fischer }\end{array}$ & 1996 & $\begin{array}{l}\text { A comparison of three neural network classifiers } \\
\text { for remote sensing classification }\end{array}$ & 8 & $\begin{array}{l}\text { Geoscience and Remote Sensing } \\
\text { Symposium, 1996. IGARSS '96. }\end{array}$ \\
\hline 4 & Blonda et al. & 1996 & $\begin{array}{l}\text { Fuzzy logic and neural techniques integration: } \\
\text { An application to remotely sensed data }\end{array}$ & 14 & Pattern Recognition Letters \\
\hline 5 & Carpenter et al. & 1997 & $\begin{array}{l}\text { ART neural networks for remote sensing: } \\
\text { vegetation classification from Landsat TM and } \\
\text { terrain data }\end{array}$ & 312 & $\begin{array}{l}\text { IEEE Transactions on Geoscience and } \\
\text { Remote Sensing }\end{array}$ \\
\hline 6 & Gopal et al. & 1999 & $\begin{array}{l}\text { Fuzzy neural network classification of global } \\
\text { land cover from a } 1^{\circ} \mathrm{AVHRR} \text { Data Set }\end{array}$ & 166 & Remote Sensing of Environment \\
\hline 7 & Liu et al. & 2001 & $\begin{array}{l}\text { Spatial data mining for classification, } \\
\text { visualisation and Interpretation with Artmap } \\
\text { Neural Network. }\end{array}$ & 17 & $\begin{array}{l}\text { Data Mining for Scientific and } \\
\text { Engineering Applications, Springer }\end{array}$ \\
\hline 8 & $\begin{array}{l}\text { Parsons and } \\
\text { Carpenter }\end{array}$ & 2003 & $\begin{array}{l}\text { ARTMAP neural networks for information } \\
\text { fusion and data mining: map production and } \\
\text { target recognition methodologies }\end{array}$ & 84 & Neural Networks \\
\hline 9 & Liu et al. & 2004 & $\begin{array}{l}\text { Uncertainty and confidence in land cover } \\
\text { classification using a hybrid classifier approach }\end{array}$ & 99 & $\begin{array}{l}\text { Photogrammetric Engineering \& Remote } \\
\text { Sensing }\end{array}$ \\
\hline 10 & $\begin{array}{l}\text { Lerner and } \\
\text { Guterman }\end{array}$ & 2008 & $\begin{array}{l}\text { Advanced developments and applications of the } \\
\text { fuzzy ARTMAP neural network in pattern } \\
\text { classification }\end{array}$ & 11 & $\begin{array}{l}\text { Computational Intelligence Paradigms, } \\
\text { Springer }\end{array}$ \\
\hline
\end{tabular}

with 5 voters, respectively. The dataset was related to the period from February 1995 to January 1996 comprising a time series (10 days) of AVHRR data (global) with Normalized Difference Vegetation Index (NDVI) information.

These authors classified the land cover using 16 classes: 1) Evergreen needle leaf forest, 2) Evergreen broadleaf forest, 3) Deciduous needle leaf forest, 4) Deciduous broadleaf forest, 5) Mixed forest, 6) Closed shrubland, 7) Open shrubland, 8) Woody savannas, 9) Savannas, 10) Grassland, 11) Permanent wetlands, 12) Cropland, 13) Urban and build-up, 14) Cropland /natural vegetation mosaic, 15) Snow and ice, 16) Barren and sparsely vegetated. Both classifiers presented low accuracy $(<$ $30 \%$ ) in classifying pixels related to the Deciduous needleleaf forest, Closed shrubland, and Woody savanna, which was attributed to the availability of poor data for the training phase. The products obtained were considered as an option to overcome the lack of data checked in-situ, due to the limitations imposed by the geographical extension as observed in the continental and/or global maps.

Lerner and Guterman (2008) present a chapter entitled "Advanced Developments and Applications of the Fuzzy ARTMAP Neural Network in Pattern Classification", which investigates the applications of FAM and its variants in general until approximately 2008. Proposals for solutions to FAM problems regarding the proliferation of categories are presented.

The authors identified a peak in 2001 in the amount of publications in general on FAM and its variants (not only referring to remote sensing) using the IEEE database. This observation, if compared with the data presented in Figure 1, sug- gests that it took approximately 8 years to diffuse FAM and its variants in the area of remote sensing research accordingly.

\section{An Overview of FAM in the Literature (and Its Variants) for Classifying Remotely Sensed Data}

The documents selected and covered in this section are listed (Table 2) to provide the reader with a glimpse, including information about their citations according to the Google Scholar database.

For the sake of organization, this section is divided accordingly into the frequency of occurrence of the application technical production that was reviewed in this paper. Therefore, two typical categories were adopted to address the occurrences of FAM in the relevant literature: A) is the FAM's predominant usage as a pixel classifier, and B) encompasses works using FAM regarding resolution, filtering, and other secondary thematic occurrences concerning the FAM's related works reviewed.

\subsection{Land Cover}

Aliabad et al. (2019) used a FAM-based method to produce a geological map of an area, which geological features had already been mapped around 1372 (year). The dataset used by these authors consisted of Multi-temporal Landsat Enhanced Thematic Mapper-plus (Landsat 8 ETM +) images endowed with a pixel resolution of $30 \times 30 \mathrm{~m}$. Boolean logic was used in the workflow to verify the results obtained as the accuracy of the maps achieved.

The kappa coefficient obtained was $89 \%$. The accuracy of 
Table 2. List of Documents, Titles, Year of Publication, and Its Citations According to the Google Scholar Dataset

\begin{tabular}{|c|c|c|c|c|c|}
\hline$\#$ & Authors & Year & Title & Cited by & Journal \\
\hline 1 & Downs et al. & 1996 & $\begin{array}{l}\text { Application of the fuzzy ARTMAP neural } \\
\text { network model to medical pattern classification } \\
\text { tasks }\end{array}$ & 81 & Artificial Intelligence in Medicine \\
\hline 2 & Mannan & 1998 & $\begin{array}{l}\text { Fuzzy ARTMAP supervised classification of } \\
\text { multi-spectral remotely-sensed images }\end{array}$ & 87 & International Journal of Remote Sensing \\
\hline 3 & $\begin{array}{l}\text { Muchoney and } \\
\text { Williamson }\end{array}$ & 2001 & $\begin{array}{l}\text { A Gaussian adaptive resonance theory neural } \\
\text { network classification algorithm applied to } \\
\text { supervised land cover mapping using } \\
\text { multitemporal vegetation index data }\end{array}$ & 43 & $\begin{array}{l}\text { IEEE Transactions on Geoscience and } \\
\text { Remote Sensing }\end{array}$ \\
\hline 4 & Han et al. & 2004 & $\begin{array}{l}\text { An improved fuzzy ARTMAP network and its } \\
\text { application in wetland classification }\end{array}$ & 6 & $\begin{array}{l}\text { IEEE International Geoscience and } \\
\text { Remote Sensing Symposium }\end{array}$ \\
\hline 5 & Amici et al. & 2004 & $\begin{array}{l}\text { A comparison of fuzzy and neuro- fuzzy data } \\
\text { fusion for flooded area mapping using SAR } \\
\text { images }\end{array}$ & 22 & International Journal of Remote Sensing \\
\hline 6 & Pugh and & 2006 & Classification of spectrally-similar land cover & 7 & IEEE International Symposium on \\
\hline 7 & Waxman & & $\begin{array}{l}\text { using multi-spectral neural image fusion and } \\
\text { the fuzzy ARTMAP neural classifier }\end{array}$ & & Geoscience and Remote Sensing \\
\hline 8 & $\begin{array}{l}\text { Statakhis and } \\
\text { Vasilakos }\end{array}$ & 2006 & $\begin{array}{l}\text { Comparison of computational intelligence- } \\
\text { based classification techniques for remotely } \\
\text { sensed optical image classification }\end{array}$ & 91 & $\begin{array}{l}\text { IEEE Transactions on Geoscience and } \\
\text { remote Sensing }\end{array}$ \\
\hline 9 & Liu and Seto & 2008 & $\begin{array}{l}\text { Using the ART-MMAP Neural Network to } \\
\text { Model and Predict Urban Growth: A } \\
\text { Spatiotemporal Data Mining Approach. }\end{array}$ & 40 & $\begin{array}{l}\text { Environment and Planning B: Planning } \\
\text { and Design }\end{array}$ \\
\hline 10 & Rogan et al. & 2008 & $\begin{array}{l}\text { Mapping land cover modifications over large } \\
\text { areas: A comparison of machine learning } \\
\text { algorithms }\end{array}$ & 203 & Remote Sensing of Environment \\
\hline 11 & Qiu & 2008 & $\begin{array}{l}\text { Neuro-fuzzy based analysis of hyperspectral } \\
\text { imagery }\end{array}$ & 36 & $\begin{array}{l}\text { Photogrammetric Engineering \& Remote } \\
\text { Sensing }\end{array}$ \\
\hline 12 & Lippitt et al. & 2008 & $\begin{array}{l}\text { Mapping selective logging in mixed deciduous } \\
\text { forest }\end{array}$ & 54 & $\begin{array}{l}\text { Photogrammetric Engineering \& Remote } \\
\text { Sensing }\end{array}$ \\
\hline 13 & Filippi et al. & 2009 & $\begin{array}{l}\text { Unsupervised fuzzy ARTMAP classification of } \\
\text { hyperspectral Hyperion data for savanna and } \\
\text { agriculture discrimination in the Brazilian } \\
\text { Cerrado }\end{array}$ & 2 & GIScience \& Remote Sensing \\
\hline 14 & Zagajewski & 2010 & $\begin{array}{l}\text { Classification of high-mountain plant } \\
\text { communities using artificial neural nets and } \\
\text { hyperspectral data }\end{array}$ & 1 & $\begin{array}{l}\text { 2nd Workshop on Hyperspectral Image } \\
\text { and Signal Processing. Evolution in } \\
\text { Remote Sensing }\end{array}$ \\
\hline 15 & $\begin{array}{l}\text { Gamba and } \\
\text { Dell'Acqua }\end{array}$ & 2010 & $\begin{array}{l}\text { Increased accuracy multiband urban } \\
\text { classification using a neuro-fuzzy classifier }\end{array}$ & 33 & International Journal of Remote Sensing \\
\hline 16 & Yanbin et al. & 2010 & $\begin{array}{l}\text { The application of improved fuzzy ARTMAP } \\
\text { neural network in remote sensing classification } \\
\text { of land use }\end{array}$ & 0 & $\begin{array}{l}\text { IEEE. Second International Conference } \\
\text { on Multimedia and Information } \\
\text { Technology }\end{array}$ \\
\hline 17 & Su et al. & 2011 & $\begin{array}{l}\text { Mapping multi-spectral remote sensing images } \\
\text { using rule extraction approach }\end{array}$ & 12 & Expert Systems with Applications \\
\hline 18 & Luo et al. & 2012 & $\begin{array}{l}\text { Classification of CBERS-2 imagery with fuzzy } \\
\text { ARTMAP classifier }\end{array}$ & 8 & Geo-spatial Information Science \\
\hline 19 & Du et al. & 2012 & $\begin{array}{l}\text { Multiple classifier system for remote sensing } \\
\text { image classification }\end{array}$ & 194 & Sensors \\
\hline 20 & Liang et al. & 2012 & $\begin{array}{l}\text { Intelligent characterization and evaluation of } \\
\text { yarn surface appearance using saliency map } \\
\text { analysis, wavelet transform and fuzzy } \\
\text { ARTMAP neural network }\end{array}$ & 28 & Expert Systems with Applications \\
\hline 21 & $\begin{array}{l}\text { Alilat and } \\
\text { Loumi }\end{array}$ & 2012 & $\begin{array}{l}\text { Fusion multispectral images by fuzzy- } \\
\text { ARTMAP }\end{array}$ & 0 & $\begin{array}{l}\text { International Conference on Multimedia } \\
\text { Computing and Systems. }\end{array}$ \\
\hline 22 & Li et al. & 2012 & $\begin{array}{l}\text { Crop region extraction of remote sensing } \\
\text { images based on fuzzy ARTMAP and adaptive } \\
\text { boost }\end{array}$ & 4 & Journal of Intelligent \& Fuzzy Systems \\
\hline 23 & Gong et al. & 2012 & $\begin{array}{l}\text { Parallelization of ensemble neural networks for } \\
\text { spatial land use modeling }\end{array}$ & 12 & $\begin{array}{l}\text { Proceedings of the } 5 \text { th International } \\
\text { Workshop on Location-Based Social } \\
\text { Networks - LBSN }\end{array}$ \\
\hline
\end{tabular}




\begin{tabular}{|c|c|c|c|c|c|}
\hline 24 & Carpenter & 2013 & $\begin{array}{l}\text { ART, cognitive science, and technology } \\
\text { transfer }\end{array}$ & 6 & $\begin{array}{l}\text { Wiley Interdisciplinary Reviews: } \\
\text { Cognitive Science }\end{array}$ \\
\hline 25 & Dai et al. & 2014 & $\begin{array}{l}\text { Adaptive terrain classification in field } \\
\text { environment based on self-supervised learning }\end{array}$ & 1 & $\begin{array}{l}\text { Proceedings of } 2014 \text { IEEE Chinese } \\
\text { Guidance, Navigation and Control } \\
\text { Conference }\end{array}$ \\
\hline 26 & Gong et al. & 2015 & $\begin{array}{l}\text { ART- P- MAP neural networks modelling of } \\
\text { land- use change: accounting for spatial } \\
\text { heterogeneity and uncertainty }\end{array}$ & 6 & Geographical Analysis \\
\hline 27 & $\begin{array}{l}\text { Chang and } \\
\text { Vaca }\end{array}$ & 2015 & $\begin{array}{l}\text { Automatic detection of clouds from aerial } \\
\text { photographs of snowy volcanoes. In: Carrasco- } \\
\text { Ochoa J., Martí-nez-Trinidad J., Sossa-Azuela } \\
\text { J., Olvera López J., Famili F. (eds) Pattern } \\
\text { Recognition. }\end{array}$ & 1 & $\begin{array}{l}\text { Lecture Notes in Computer Science, } \\
\text { Springer }\end{array}$ \\
\hline 28 & Li et al. & 2015 & $\begin{array}{l}\text { Crop region extraction of remote sensing } \\
\text { images based on fuzzy ARTMAP and adaptive } \\
\text { boost }\end{array}$ & 4 & Journal of Intelligent \& Fuzzy Systems \\
\hline 29 & Wu et al. & 2016 & $\begin{array}{l}\text { Adaptive pixel unmixing based on a fuzzy } \\
\text { ARTMAP neural network with selective } \\
\text { endmembers }\end{array}$ & 3 & Soft Computing \\
\hline 30 & $\begin{array}{l}\text { Gorji- } \\
\text { Chakespari et } \\
\text { al. }\end{array}$ & 2016 & $\begin{array}{l}\text { Performance comparison of fuzzy ARTMAP } \\
\text { and LDA in qualitative classification of Iranian } \\
\text { Rosa Damascena essential oils by an electronic } \\
\text { nose }\end{array}$ & 13 & Sensors \\
\hline 31 & Wu et al. & 2017 & $\begin{array}{l}\text { Sub-pixel mapping based on MAP model and } \\
\text { spatial attraction theory for remotely sensed } \\
\text { image }\end{array}$ & 2 & IEEE Access \\
\hline 32 & Yahiaoui et al. & 2017 & $\begin{array}{l}\text { Parallelization of fuzzy ARTMAP architecture } \\
\text { on FPGA: multispectral classification of } \\
\text { ALSAT-2A Images }\end{array}$ & 3 & $\begin{array}{l}\text { IEEE Transactions on Industrial } \\
\text { Electronics }\end{array}$ \\
\hline 33 & Han et al. & 2018 & $\begin{array}{l}\text { Object-wise joint-classification change } \\
\text { detection for remote sensing images based on } \\
\text { entropy query-by fuzzy ARTMAP }\end{array}$ & 6 & GIScience \& Remote Sensing \\
\hline 34 & $\begin{array}{l}\text { Matias and } \\
\text { Rocha }\end{array}$ & 2018 & $\begin{array}{l}\text { OnARTMAP: A fuzzy ARTMAP-based } \\
\text { architecture }\end{array}$ & 8 & Neural Networks \\
\hline 35 & Silva et al. & 2019 & $\begin{array}{l}\text { A survey of adaptive resonance theory neural } \\
\text { network models for engineering applications }\end{array}$ & 7 & Neural Networks \\
\hline
\end{tabular}

the method, driven by FAM, was verified against the ancient map (1372) besides other methods (information sources). Based on these results, the authors concluded that the method can be recommended for low-cost mapping of these geological features of extended areas.

Han et al. (2018) present a method for land cover change detection using an object-based entropy query-by-FAM joint classification and also offer a case study related to the Liahoe estuary wetland (China) regarding the period from 1987 to 2014. This method aimed to address issues inferred in the postclassification comparison, specifically error accumulation and the so-called salt and pepper effect regarding digital image processing. This approach is based on an initial iterative procedure called Active Learning-based Entropy query-by FAM (EQFAM) used to optimize data selection for machine learning training, among those used for the purpose of detecting land cover change through classification and comparison. The EQFAM method includes calculating a similarity matrix and a corresponding threshold supported by the spectral vector of the images then converging to the definition of the reference pixels. In the next step, class labels for the reference pixel are defined allowing a joint classification of the total image. The final step is the object wise change detection using entropy rate, sup- ported by superpixel definition and a majority-voting rule. These authors concluded that the method achieves a reduction in the error accumulation and the salt and pepper effect. Consequently, greater accuracy was observed when detecting changes compared to the state-of-the-art according to these authors.

Regarding the task of classifying multispectral Images captured by sensors on board the ALSAT-2A satellite, Yahiaoui et al. (2017) describe a coarse grain parallelization of the FAM algorithm. This paper presents a discussion on hardware features regarding FAM's implementation using FPGA (Field Programmable Gate Array) technology. Specifically, a full parallel and pipelined FAM setup with an eight-bit precision was discussed.

Li et al. (2015) propose a method for the optimization of the procedure of crop (a land use category) extraction by processing remotely sensed scenes using FAM. Additionally, the selection of training data oriented by an active learning approach called the ADABOOST strategy was included in the methodology. After defining the optimal training dataset, the FAM was used to extract the crop area based on R, G, B and near-infrared) and panchromatic (pan) images at pixel resolution of $2 \times 2 \mathrm{~m}$. The results outperformed the traditional supervised learning approach used in a benchmark comparison ac- 
cording to these authors. A probability driven variant of the FAM was presented by Gong et al. (2015). The case study in this work aimed to detect changes in land use. The authors recommend that this type of problem should be addressed through probabilistic regression and not soft computing.

The FAM variant obtained under the probability bias was considered robust to build neural networks structures based on data affected by noise and spatial variability, as typically occurs with remote sensing images, according to these authors. Dai et al. (2014) used data produced by 3D laser scanning sensing for training a FAM to guide the movement of robots across obstacles. After the robot initial operation and supported by the robot signaling system, the plasticity of the FAM grounded a self-learning system to improve the movements of the robot on the terrain due to preservation and accumulation of learned experiences according to these authors. A self-supervised approach inspired by FAM was tested by Carpenter (2013). The land cover classification and related tests using the Boston testbed were performed. This was done to evaluate a trade-off between supervised learning and unsupervised learning.

This Boston related dataset is derived from images acquired by Thematic Mapper (TM) sensors on board the Landsat-7 using 2 thermal bands with a pixel resolution of $60 \times 60$ $\mathrm{m}, 1$ panchromatic band with a pixel resolution of $15 \times 15 \mathrm{~m}$ and other bands with color and texture data. This study area measures $5.4 \times 9.0 \mathrm{~km}$ and includes portions of northeast Boston city and its suburbs. This area is represented by a total of 216000 pixels, $10 \%$ of which are labelled as representative of the ocean class. Other represented classes are mixed urban, suburban, industrial, water, and park spaces. Ground-truth pixels are related to the ocean, ice, river, beach, park, residential, and industrial. After the learning stage, the average accuracy achieved in the pixel classification task was $89.4 \%$.

In another investigation, Du et al. (2012) proposed a discussion about the use of multiple classifiers (i.e., an ensemble approach) including the simplified FAM as an option tested as a component of this ensemble. This work used high-resolution images (Quickbird) of the northern suburb of Xuzhou city in China. The following classes were considered in the classification of water, built-up area, green areas, vegetation, and barren soil. The simplified FAM outperformed the other 6 classifiers tested on the green area class considering only spectral features as the data input. The consideration of textural characteristics made the simplified FAM more accurate than the other classifiers, also regarding the representative class of arid soil.

Gong et al. (2012) described an approach for detecting spatial changes in land use based on using a set of FAM. According to these authors, this methodology via sets, performed better than MLC and other options of neural networks architectures. These authors claim that the FAM is naturally endowed with aptitude for parallel processing. They also state that the proposed method allows the optimal use of the training dataset as it is based on training multiples networks.

The inputted data to the model was designed to represent spatial proximity, neighborhood, and physical features of the Cleveland-Akron-Elyria Metropolitan Area (USA). The land use change information used in this paper (at a pixel resolution of $30 \times 30 \mathrm{~m}$ ) from the period from 1992 to 2001 was generated using the United States Geological Survey (USGS) National land cover dataset. The observation that the best performance was achieved by increasing the size of the training dataset suggested to these authors that the parallelism provided by using FAM indeed has positive potentialities.

Regarding land use in tropical regions, Li et al. (2012) explore the use of FAM classifiers to cluster land use using data obtained from sensors on board the ALOS (Advanced Land Observing Satellite). Specifically, the sensor PALSARL-band (Phased Array type L-band Synthetic Aperture Radar) with a pixel resolution of $12.5 \times 12.5 \mathrm{~m}$. Data produced by the RADARSAT-2 C-band data in the standard beam mode with a pixel resolution of $8 \times 8 \mathrm{~m}$ was also used.

The studied site was the municipality located along the pathway of the Transamazon Highway (BR-230) called Altamira on the northern Brazilian state of Para. Concerning a specific sensor (data), the best results were obtained with data relating to the L band (microwave). Both decision-tree and FAM classifiers outperformed the MLC overall by a 3.3\% increase in the accuracy value compared with the accuracy of other classifiers tested in the same task.

FAM as a classifier of the data obtained by CBERS-2 (China-Brazil Earth Resources Satellite) for Shihezi, Xinjiang (China) was the main topic of research carried out by Luo et al. (2012). Four bands were used as data input: $0.45 \sim 0.52,0.52$ $\sim 0.59,0.63 \sim 0.69$ and $0.77 \sim 0.89 \mu \mathrm{m}$ with a pixel resolution of $19.5 \times 19.5 \mathrm{~m}$. The 6 classes used for the classification task were: water, bare land, dry plantation, irrigable land, and saline land. The total accuracy obtained by FAM was $97.70 \%$, 93.09\% for backpropagation (ANN), and $88.82 \%$ for MLC. It was stated that FAM outperformed the other 2 classifiers based on the total kappa coefficient and total accuracy, which was the index used for evaluation purposes by these authors.

On the framework of another FAM derived architecture, Su et al. (2011) compare the variant of FAM called simplified FAM (SFAM) with a neural network of the Hyper Rectangular Composite Neural Network class (HRCNN) that presents both features that related to rule-based inference and that of neural networks. Another characteristic of this type of HRCNN is to present supervised decision directed learning (SDDL) according to these authors. This neural network was then compared with the SFAM on the task of classifying land cover. The dataset used comprised images obtained by the DS1260 MultiSpectral Scanner (MSS) captured over Taoyuan Country on the quadrangle representing Shi-Men Dam using $512 \times 512$ pixels. On a pixel-by-pixel classification approach using forest, water, and build-up as classes, an overall accuracy of $98.85 \%$ by the HRCNNs was observed and compared with $98.37 \%$ obtained by SFAM under test.

Another proposition of a simplified FAM was tested by Yanbin et al. (2010). According to these authors, this variant of FAM would be more suitable for the classification of multidimensional and larger data compared to the original version of FAM. This improvement was related to an alternative approach 
to the original FAM's complementation algorithm. This hypothesis was tested using ETM images of Yiwu City (China) in the land use classification task. These authors obtained a classification accuracy of $88.26 \%$ using a multilayer Perceptron ANN (trained with the backpropagation algorithm) and $90.99 \%$ with the simplified FAM that also performed better concerning computational time according to these authors.

Zagajewski (2010) reports on the mapping of plant groups in two polygons in alpine and subalpine zones in the Tatra National Park, in southern Poland, in the Carpathian Mountains (Czech Republic). The hyper-spectral data produced by the Digital Aerial Image Spectrometer (DAIS) 7915 were used as data inputs from FAM that classified them into 42 classes. The best accuracy was obtained in an experiment using 40 selected bands when the value of $87 \%$ was reached. The time required for training this network was pointed out as an inconvenience in this case of study.

Gamba and Dell'Acqua (2010) considered FAM as the best classifier, with data input from multiple bands (frequencies), tested in a workflow that used data from the Airborne Visible Infrared Imaging Spectrometer (AVIRIS). This methodology was also supported by a step of reduction of dimensionality using the Decision Boundary Feature Extraction (DBFE) adaptive transform technique.

An unsupervised FAM usage for mapping the Brazilian Cerrado was described by Filippi et al. (2009) using hyperspectral satellite data. The Unsupervised FAM mapping performed better than the k-means approach used in the comparison. A parametrization to maximize classification accuracy for the dataset of images used was defined. The best accuracy in the classification was achieved for open "cerrado" grassland and wooded "cerrado". The worst performance in the accuracy of the classification related to the agricultural class of information was highlighted in this paper.

Qiu (2008) reviewed articles that show criticisms of FAM in terms of its sensitivity to outliers and noise that lead to a decrease in accuracy in the classification task. This was stated as part of the justification for proposing an alternative to FAM called the Gaussian Fuzzy Learning Vector Quantization (GFLVQ) considered by the authors as a better classifier, for hyperspectral data compared to FAM.

Lippitt et al. (2008) evaluated 5 machine learning algorithms for mapping the selective logging in mixed deciduous forests. Among these algorithms, one related to FAM was identified as ARTMAP. For this application, the classification-tree approach was considered more suitable comparatively. These authors stated that the ARTMAP has the advantage of eliminating the necessity of prior knowledge about data structure allowing an empirical definition of the number of neurons, intuittive parametrization and relatively easy usage. However, the performance of ARTMAP in the classification task decreased as a result of the reduction in the size of the training set or due to the introduction of noise in this dataset compared to the classification-tree and self-organizing map options.

A set of 3 classifiers was compared concerning the task of changing the detection of landscape in California (USA) (Ro- gan et al., 2008). The data used in the test consisted of multitemporal Landsat sensors' products and also environmental ground-level data. Among the three considered classifiers, the most suitable for the task was the FAM and it was considered more robust against noise presence in the training dataset in this case study according to these authors.

Liu and Seto (2008) proposed ART-MMAP as a regression model that captures urban growth patterns and allows them to predict it on the framework of spatially dynamic modeling approaches. This variant architecture of FAM called ARTMMAP differs from that one as it was modified regarding the testing phase. A different strategy to select the best classification produces an improved interpolation function in relation to the original according to these authors. In this case, this interpolation function could be interpreted as an operator that represents a weighted sum, according to Liu and Seto (2008). Relying strongly on GIS (geographic information systems) and land use map information, the following features were observed concerning the ART-MMAP: 1) it is fast, it does not demand interventions and has automatic calibration, 2) its learning capability captures the complex pattern of urban growth, and 3) presents accurate predictions under different scenarios of development. The results obtained were considered to consistently outperform a naive model and also two other randomly chosen.

Statakhis and Vasilakos (2006) reviewed and compared some cases studies described in the literature and point out some benefits and disadvantages of this architecture. The advantage is that it has few parameters to adjust to operate. The drawback is the lack of robustness regarding avoiding excessive noise in the data, as well as a low resilience concerning the effects of local minimums according to them.

Pugh and Waxman (2006) presented a method inspired by the human visual processing system. This system has an image fusion stage supported by neural networks (feed-forward center-surround shunting networks) to process thermal infrared and recorded panoramic among other images. The produced image generated by fusion was then classified on a second step using a variant FAM as the classifier to identify the individual coniferous species using multi-season LANDSAT's sensor imagery of a forest located in a central region of New York. In this step, unsupervised category learning, supervised class association, and a saliency detection algorithm were combined. These authors obtained detection probabilities better than $70 \%$ for individual coniferous species despite the considered climatological season.

Han et al. (2004) proposed a variant of FAM. The improvement proposed by them is based on modifying the FAM's $\mathrm{ART}_{\mathrm{a}}$ by relating it to fuzzy rules. The classification of land cover on 9 classes concerning a wetland nature reserve in north China called Zhalong was done using an input vector of data containing second-order textural data and spectral bands (related to vegetation sensed by the TM sensor). This variant FAM out-performed the original FAM on overall accuracy of classification by approximately $5 \%$.

Two options of methods were investigated including FAM to analyze if it would be better to approach a flooded area map- 
ping using multitemporal contextual analysis or a combination of single data using fuzzy tools (Amici et al., 2004). The performed test used data consisting of images produced by SAR (synthetic aperture radar) sensors on board the ERS-1/2 (European Remote Sensing Satellite) and also the Radarsat. These data relate to the Pavia Northern region of Italy and were obtained at C-band $(5.3 \mathrm{GHz})$ and polarization (VV, HH). FAM was used as the core of a procedure consisting of a neuro-fuzzy joint classification in a workflow composed of per-pixel classification and spatial processing (reprocessing of the first map to consider the neighborhood of each pixel). This workflow with the neuro-fuzzy classification resulted in greater accuracy in the classification, but in order to achieve products with an accuracy greater than $90 \%$, the initial experimental design had to be modified to introduce additional spatial and temporal considerations regarding the data used.

Muchoney and Williamson (2001) compared the FAM and other classifiers with the performance of the variant named Gaussian ARTMAP (GART), which main difference in relation to the FAM is that it is based on the mean and variance instead of an interval mathematical approach. Comparing accuracy in the same task of classification of remotely sensed data, it was inferred that the original FAM achieved $79 \%$ while GART obtained $83 \%$ accuracy. This test was performed in a land use classification task (using 17 classes) with data from a central America region composed by monthly annual NDVI series produced by the AVHRR sensor.

A FAM setup was compared with an ANN multi-layer perceptron trained with the backpropagation algorithm (MLP) and the MLC classifier (Mannan, 1998). Multi-spectral imagery was produced by the sensor LISS-II (Linear Imaging SelfScanner) of the Indian Remote Sensing satellite (IRS-1B). It was considered that the VLSI (hardwired) implementation of fuzzy FAM would enable near real-time image classification. The stability of the learning and operating phases and the low effort required for parameterization were also positively emphasized regarding FAM, including the definition of initial weights. Six datasets were tested and the lowest accuracy inferred of the FAM classifier was $74.55 \%$ compared with $70.39 \%$ for MLP and $72.22 \%$ for MLC. The highest FAM result was $94.96 \%$ compared with $88.18 \%$ for MLP and $89.69 \%$ for MLC (Mannan, 1998).

\subsection{Alternative FAM Usages: Pixel Resolution/Filtering and Others}

FAM was used in the final stage of a procedure to obtain a sub-pixel mapping (Wu et al., 2017). The initial step relied on a maximum posterior iterative algorithm (MAP) used to offer an improved resolution for images. The data's input vector of the FAM related to coarse pixels, the output of this setup was the forecasted subpixels. The MAP + FAM approach was considered capable of capturing non-linear features and outperformed existing options for this scaling. The experimental verification was done using a multi-spectral SPOT (Satellite Pour l'Observation de la Terre) at a pixel resolution of $10 \times 10 \mathrm{~m}$ of Nanjing city in China. The approach, based exclusively on a
FAM, generated a map with some issues such as in blocks of urbanization areas in the city class and also in a wrong discontinuity of a section of vegetation within the scope of the land use classification (Wu et al., 2017). Wu et al. (2016) offer a method to modify a pixel unmixing method that relies on FAM. Landsat's $(\mathrm{TM})$ images at a pixel resolution of $30 \times 30 \mathrm{~m}$ spatial covering the area of Yichang (China) was used. The authors state that an approach using FAM is inherently apt for this operation focused in the called endmembers.

Two schemes were presented by Alilat and Loumi (2012) for the fusion of multispectral (MS) and panchromatic images both of them supported by the FAM architecture. One relies uniquely on a single FAM setup, called global, and the other one relies on 3 FAM that handled each one of the 3 bands of the images used. The study used IKONOS satellite images endowed with pixel resolutions of $1 \times 1 \mathrm{~m}(\mathrm{Pan})$ and $4 \times 4 \mathrm{~m}(\mathrm{MS})$ and the QuickBird satellite at $0.61 \times 0.61 \mathrm{~m}(\mathrm{Pan})$ and $2.44 \times$ $2.44 \mathrm{~m}$ (MS). The quality of this fusion process was inferred using two levels of color and also selected preservation of details as checkpoints. The second approach was considered promising in the task of fusing low-resolution images with details provided by the high-resolution images. However, an observation was also made about the need for studies regarding finetuning some specific parameters.

Chang and Vaca (2015) describe a method supported by the FAM capacity of classification that, jointly with an image thresholding step, allowed cloud detection in aerial photographs (RGB) of volcanos with the challenging snow-capes presence using $32 \times 32$ pixel images. These authors achieved accuracy of $91.4 \%$ in this cloud detection task by using the FAM's fast learning mode and $95.5 \%$ accuracy by using the slow learning mode.

\subsection{Supplementary Resources}

Code repositories related to ART (FAM included) are available online. One of them is maintained by one of the creators of the FAM architectures and can be found online (Carpenter, 2018). Additionally, information about these available code repositories are addressed elsewhere (Silva et al., 2019).

Some initial paths a person can take to start using FAM and its variants in other fields of application and or whoever wants to explore its theoretical aspects could study for example Downs et al. (1996) for medical applications, Gorji-Chakespari et al. (2016) on instrumentation (electronic nose), Liang et al. (2012) that deal with textile quality control and Matias and Rocha (2018) that address some theoretical computational aspects about FAM.

\section{Discussion and Conclusion}

The frequency of usage of the FAM classifier for land use/change detection mapping tasks suggests that this is indeed an already consolidated application of artificial neural networks. In this context, a greater level of detail on using FAM seems to be necessary. Therefore, studies about the full set of aspects related to the daily/operational routine of a person using FAM to 
produce maps such as: capacity building and training requirements, financial characteristics, records of typical troubleshooting, optimization of workflow and data management specificities could help consolidate even more the use of FAM in land use mapping.

Another possible gap in the related literature seems to be the lack of a comprehensive and organized "road map" paper focused only on the wide range of FAM's variants in the context of remotely sensed data. Ideally, this paper could make a detailed comparison of the variants, including a pairwise comparison approach to allow one select reference parameters focused on remote sensing data. It could also present in-depth details about the parametrization and computational requirements of each one of these available FAM related classifiers options. This paper may provide a type of taxonomy with some kind of numerical distance between each variant of the original FAM organized in a hierarchical structure following that inspired by the so-called phylogenetic tree.

This future article could discuss the variants of FAM regarding robustness, in the classification task, regarding the proliferation of categories, as well as the effects of the order of presentation of each example in the training phase because these are recurring themes related to FAM issues. Moreover, some focus on the financial aspects concerning one choice among the FAM related classifiers could possibly deserve more detailed research and scientific communication. Additionally, a study focusing specifically on the hard-ware implementation of FAM (and its variants) classifiers focusing on the requirements to be considered by one who intend to use this hardware as an onboard load of vehicles, especially, the unmanned ones could perhaps be relevant for this field of research.

Perhaps it would be worthwhile, despite the considerable availability of a number of comparative studies on the suitability of FAM for mapping tasks, to make an effort to describe this type of comparison, focusing not on the sensor and image /sensor pair, but on moving to a lower level of abstraction, that is, in the features descriptors of these images. It is clear that this is not a priority, but it could potentially promote details of this branch of scientific research and provide a common "denominator" to compare the performance of these classifiers more independently from the sensors in question.

Approximately 30 years after its original version was proposed, the FAM concept has still been triggering scientific activities and the evidence seen in this paper suggests that it will, to some extent, continue to occur. Indeed, despite being considered a mature field of research, the larger framework of FAM, ART still presents opportunities (Silva et al., 2019).

It is notorious that deep learning-based solutions have gained ground in recent years in classification tasks using remotely sensed data. Especially, in those related to large dataset availability and when the classifier interpretability is not an important feature. Conversely, in future scenarios regarding the use of FAM and its variants for mapping purposes, perhaps the use of this classifier for tasks with a low/intermediate complexity and or when interpretability is necessary, will be consolidated as a preferential use of the FAM that typically relates to shallow learning. These characteristics seem to partially resonate with the FAM applications on dynamical tasks to be executed by autonomous vehicles as remote sensing platforms (aerial, terrestrial, and others) supported by its online learning capacity. FAM would be implemented in dedicated onboard hardware producing maps to guide autonomous navigation. This kind of application was detected by the literature overview presented here indeed.

However, the increase in the production capacity of large datasets by the various remote sensing platforms tends naturally to promote deep learning solutions, to the detriment of methodologies based on FAM and its variants. It should be noted, however, that some new variants of the FAM may significantly affect this "competition" between concepts inherent to scientific development.

Acknowledgments. This study was financed in part by the Coordenação de Aperfeiçoamento de Pessoal de Nível Superior-Brasil (CAPES)-Finance Code 001

\section{References}

Aliabad, F.A., Shojaei, S., Zare, M., and Ekhtesasi, M.R. (2019). Assessment of the Fuzzy ARTMAP neural network method performance in geological mapping using satellite images and Boolean logic. International journal of environmental science and technology, 16, 3829. https://doi.org/10.1007/s13762-018-1795-7

Aliabad, F.A., Hakimzadeh, M. and Shojaei, S.S. (2019). An image coding/decoding method based on direct and inverse fuzzy transforms. Water Resources Management, 5, 541. https://doi.org/10. 1007/s40899-017-0204-6

Alilat, F. and Loumi, S. (2012). Fusion multispectral images by fuzzyARTMAP. International Conference on Multimedia Computing and Systems, 174-177. https://doi.org/10.1109/ICM CS.2012.6320234

Amici, G., Dell'acqua, F., Gamba, P. and Pulina, G. (2004). A comparison of fuzzy and neuro - fuzzy data fusion for flooded area mapping using SAR images. International Journal of Remote Sensing, 25, 4425-4430. https://doi.org/10.1080/014311604123 31269634

Binaghi, E., Brivio, P.A., Rampini, A. and Schowengerdt, R.A. (1996) Special issue on non-conventional pattern analysis in remote sensing Pattern Recognition Letters. Pattern Recognition Letters, 17 (13), 1323-1324. ISSN 0167-8655. https://doi.org/10.1016/S 01678655(96)00088-8

Blonda, P., Bennardo, A., Satalino, G., and Pasquariello, G. (1996). Fuzzy logic and neural techniques integration: an application to remotely sensed data. Pattern Recognition Letters, 17(13), 13431348. https://doi.org/10.1016/S0167-8655(96)00091-8

Carpenter, G. A. (2018). http://www.cns.bu.edu/ ARTMAP/

Carpenter, G.A., Grossberg S. and Rosen D.B. (1991). Fuzzy ART: Fast stable learning and categorization of analog patterns by an adaptive resonance system, Neural Networks, 4, 759-771. https://doi.org/10. 1016/0893-6080(91)90056-B

Carpenter, G.A., Grossberg, S., Markuzon, N., Reynolds, J.H. and Rosen, D.B. (1992). Fuzzy ARTMAP: A neural network architectture for incremental supervised learning of analog multidimensional maps. In IEEE Transactions on Neural Networks, 3(5), 698-713. https://doi.org/10.1109/72.159059

Carpenter, G.A., Gjaja, M.N., Gopal, S. and Woodcock, C.E. (1997). ART neural networks for remote sensing: vegetation classification from Landsat TM and terrain data, In IEEE Transactions on Geoscience and Remote Sensing, 35(2), 308-325. https://doi.org $/ 10.1109 / 36.563271$

Carpenter, G.A. (2013), ART, cognitive science, and technology 
transfer. Wiley Interdisciplinary Reviews: Cognitive Science, 4: 707 719. https://doi.org/10.1002/wcs. 1260

Chang C. and Vaca F. (2015) Automatic Detection of Clouds from Aerial Photographs of Snowy Volcanoes. In Mexican Conference on Pattern Recognition, 9116. Springer, Cham.

Dai, X., Li, S. and Sun, F. (2014). Adaptative terrain classification in field environment based on self-supervised learning. Proceedings of 2014 IEEE Chinese Guidance, Navigation and Control Conference, Yantai, 6-11. https://doi.org/10.1109/CGNCC.201 4.7007211

Dehghani, A.A., Bahremand, A.R., and Shojaei, S. (2017). Intelligent estimation of flood hydrographs using an adaptive neuro-fuzzy inference system (ANFIS). Modeling Earth Systems and Environment, 3(1), 35. https://doi.org/10.1007/s40808-017-0305-0

Eslami, Z., Shojaei, S. and Hakimzadeh, M.A. (2017). Exploring prioritized sub-basins in terms of flooding risk using HEC_HMS model in Eskandari catchment, Iran. Spatial Information Research, 25(5), 677-684. https://doi.org/10.1007/s41324-017-0135-1

Downs, J., Harrison, R.F., Kennedy, R.L. and Cross, S.S. (1996). Application of the fuzzy ARTMAP neural network model to medical pattern classification tasks, Artificial Intelligence in Medicine. Artificial Intelligence in Medicine, 8(4), 403-428. https: //doi.org/10.1016/0933-3657(95)00044-5

Du, P., Xia, J., Zhang, W., Tan, K., Liu, Y. and Liu, S. (2012). Multiple classifier system for remote sensing image classification: A review. Sensors, 12(4), 4764-4792. https://doi.org/10.3390/s 120404764

Ferreira, A.G., Soria, E., López, A.J.S., and Lopez-Baeza, E. (2010) Characterization and Modelization of Surface Net Radiation through Neural Networks. In Soft Computing Methods for Practical Environment Solutions: Techniques and Studies, (pp. 260-277). IGI Global. https://doi.org/10.4018/978-1-61520-893 -7.ch016

Filippi, A.M., Brannstrom, C., Dobreva, I., Cairns, D.M. and Kim, D. (2009). Unsupervised fuzzy ARTMAP classification of hyperspectral Hyperion data for savanna and agriculture discrimination in the Brazilian Cerrado. GIScience and Remote Sensing, 46(1), 1-23. https://doi.org/10.2747/1548-1603.46.1.1

Gamba, P. and Dell'Acqua, F. (2010). Increased accuracy multiband urban classification using a neuro-fuzzy classifier. International Journal of Remote Sensing, 24(4), 827-834, https://doi.org/10.1080/ 01431160210154001

Gong, Z., Tang, W. and Thill, J.C. (2012). Parallelization of ensemble neural networks for spatial land use modeling. Proceedings of the 5th International Workshop on Location-Based Social Networks LBSN '12.48-54. https://doi.org/10.1145/2442796.2442808

Gong, Z., Thill, J. and Liu, W. (2015). ART - P - MAP Neural Networks Modelling of Land - Use Change: Accounting for Spatial Heterogeneity and Uncertainty. Geographical Analysis, 47, 376409. https://doi.org/10.1111/gean.12077

Gopal, S. (2016). Artificial Neural Networks in Geospatial Analysis. In International Encyclopedia of Geography: People, the Earth, Environment and Technology. https://doi.org/10.1002/9781118786 352.wbieg0322

Gopal, S. and Fischer, M. (1996). A comparison of three neural network classifiers for remote sensing classification. Geoscience and Remote Sensing Symposium, 1996. IGARSS '96. 'Remote Sensing for a Sustainable Future. International, Lincoln, NE, 1, 787-789.

Gopal, S., Woodcock, C.E. and Strahler, H.A. (1999). Fuzzy Neural Network Classification of Global Land Cover from a $1^{\circ}$ AVHRR Data Set. Remote Sensing of Environment, 67(2), 230-243. https: //doi.org/10.1016/S0034-4257(98)00088-1

Gorji-Chakespari, A., Nikbakht, A.M., Sefidkon, F., GhasemiVarnamkhasti, M., Brezmes, J. and Llobet, E. (2016). Performance Comparison of Fuzzy ARTMAP and LDA in Qualitative Classification of Iranian Rosa damascena Essential Oils by an Electronic Nose. Sensors, 16, 636. https://doi.org/10. 3390/s16050636

Han, M., Tang, X. and Cheng, L. (2004). An improved fuzzy
ARTMAP network and its application in wetland classification, IGARSS 2004. IEEE International Geoscience and Remote Sensing Symposium, 5, 3432-3435.

Han, M., Zhang, C. and Zhou, Y. (2018). Object-wise joint-classification change detection for remote sensing images based on entropy query-by fuzzy ARTMAP, GIScience and Remote Sensing, 55(2), 265-284, https://doi.org/10.1080/154816 03.2018.1430100

Harzing, A.W. (2007) Publish or Perish, available from https://harzing. com/resources/publish-or-perish

Lerner, B. and Guterman, H. (2008). Advanced developments and applications of the fuzzy ARTMAP neural network in pattern classification. In Computational intelligence paradigms (77-107). Springer, Berlin, Heidelberg. https://doi.org/10.1007/978-3-540-79 4745_4

Li, G., Lu, D., Moran, E., Dutra, L., and Batistella, M. (2012). A comparative analysis of ALOS PALSAR L-band and RADARSAT$2 \mathrm{C}$-band data for land cover classification in a tropical moist region. ISPRS Journal of Photogrammetry and Remote Sensing, 70, 26-38. https://doi.org/10.1016/j.isprsjprs.20 12.03.010

Li, D.W., Yang, F.B. and Wang, X.X. (2015). Crop region extraction of remote sensing images based on fuzzy ARTMAP and adaptive boost. Journal of Intelligent and Fuzzy Systems, 29(6), 2787-2794. https://doi.org/10.3233/IFS-151983

Liang, Z., Xu, B., Chi, Z. and Feng, D. (2012). Intelligent characterization and evaluation of yarn surface appearance using saliency map analysis, wavelet transform and fuzzy ARTMAP neural network. Expert Systems with Applications, 39(4), 42014212. https://doi.org/10.1016/j.eswa.2011.09.114

Lippitt, C.D., Rogan, J., Li, Z., Eastman, J.R. and Jones, T.G. (2008). Mapping selective logging in mixed deciduous forest. Photogrammetric Engineering \& Remote Sensing, 74(10), 1201-1211. https://doi.org/10.14358/PERS.74.10.1201

Liu, W. and Seto, K.C. (2008). Using the ART-MMAP Neural Network to Model and Predict Urban Growth: A Spatiotemporal Data Mining Approach. Environment and Planning B: Planning and Design, 35 (2), 296-317. https://doi.org/10.1068/b3312

Liu, W., Gopal, S. and Woodcock, C.E. (2004). Uncertainty and confidence in land cover classification using a hybrid classifier approach. Photogrammetric Engineering and Remote Sensing, 70(8), 963-971. https://doi.org/10.14358/PERS.70.8.963

Liu, W., Gopal, S. and Woodcock, C. (2001). Spatial Data Mining for Classification, Visualization and Interpretation with Artmap Neural Network. In Data mining for scientific and engineering applications (pp. 201-221). Springer, Boston, MA. https://doi.or g/10.1007/9781-4615-1733-7_12

Luo, C., Liu, Z. and Yan, Q. (2012). Classification of CBERS-2 imagery with fuzzy ARTMAP classifier. Geo-spatial Information Science, 10(2), 124-127, https://doi.org/10.1007/s11806-007-004 3$\mathrm{y}$

Mannan, B., Roy, J. and Ray, A.K. (1998). Fuzzy ARTMAP supervised classification of multi-spectral remotely-sensed images. International Journal of Remote Sensing, 19(4), 767-774, https://doi.org/ $10.1080 / 014311698215991$

Mas J.F. and Flores J.J. (2008) The application of artificial neural networks to the analysis of remotely sensed data. International Journal of Remote Sensing, 29(3), 617-663, https://doi.org/10.10 $80 / 01431160701352154$

Mather, P., and Tso, B. (2016). Classification methods for remotely sensed data. CRC press. https://doi.org/10.1201/9781420090741

Matias, L.S. and Rocha Neto, A. (2018). OnARTMAP: A Fuzzy ARTMAP-based Architecture. Neural Networks, 98, 236-250. https: //doi.org/10.1016/j.neunet.2017.11.012

Muchoney, D. and Williamson, J. (2001). A Gaussian adaptive resonance theory neural network classification algorithm applied to supervised land cover mapping using multitemporal vegetation index data, In IEEE Transactions on Geoscience and Remote 
Sensing, 39(9), 1969-1977. https://doi.org/10.1109/36.951087

Parsons, O. and Carpenter, G. A. (2003). ARTMAP neural networks for information fusion and data mining: map production and target recognition methodologie. Neural Networks, 16, 1075. https://doi.o rg/10.1016/S0893-6080(03)00007-8

Pugh, M. and Waxman, A. (2006). Classification of Spectrally-Similar Land Cover Using Multi-Spectral Neural Image Fusion and the Fuzzy ARTMAP Neural Classifier. IEEE International Symposium on Geoscience and Remote Sensing, 1808-1811. https://doi.org/ 10.1109/IGARSS.2006.467

Qiu, F. (2008). Neuro-fuzzy Based Analysis of Hyperspectral Imagery. Photogrammetric Engineering and Remote Sensing, 1235-1247. https://doi.org/10.14358/PERS.74.10.1235

Rastegaripour, F., Saboni, M. S., Shojaei, S. and Tavassoli, A. (2019). Simultaneous management of water and wastewater using ant and artificial neural network (ANN) algorithms. International Journal of Environmental Science and Technology, 16(10), 5835-5856. https: //doi.org/10.1007/s13762-018-1943-0

Rogan, J., Franklin,J., Stow, D., Miller,J., Woodcock, C. and Roberts, D. (2008). Mapping land cover modifications over large areas: A comparison of machine learning algorithms. Remote Sensing of Environment, 112(5), 2272-2283. https://doi.org/10.1016/j.rse.2007. 10.004

Salah, M. (2017). A survey of modern classification techniques in remote sensing for improved image classification. Journal of Geomatics. 11(1), 21.

Silva L.E.B, Elnabarawy I. and Wunsch, D.C. (2019) A survey of adaptive resonance theory neural network models for engineering applications. Neural Networks, 120, 167-203, ISSN 0893-6080 https://doi.org/10.1016/j.neunet.2019.09.012

Škrjanc, I., Iglesias, J.A., Sanchis, A., Leite, D., Lughofer, E. and Gomide, F. (2019). Evolving fuzzy and neuro-fuzzy approaches in clustering, regression, identification, and classification: A survey. Information Sciences, 490, 344-368. https://doi.org/10.1016/j.ins. 2019.03.060
Stathakis, D. and Vasilakos, A. (2006). Comparison of computational intelligence based classification techniques for remotely sensed optical image classification, In IEEE Transactions on Geoscience and Remote Sensing, 44(8). 2305-2318, https://doi.org/10.1109/ TGRS.2006.872903

Su, M.C., Huang, D.Y., Chen, J.H., Lu, W.Z., Tsai, L.C. and Lin, J.Z. (2011). Mapping multi-spectral remote sensing images using rule extraction approach. Expert Systems with Applications, 38(10), 12917-12922. https://doi.org/10.1016/j.eswa.2011.04.086

Webster, J.G., Baruah, R.D., Angelov, P.P. and Baruah, D. (2020). Evolving Intelligent Systems. In Wiley Encyclopedia of Electrical and Electronics Engineering, J.G. Webster (Ed.). https://doi.org/ 10.1002/047134608X.W8405

Wu, K., Du, Q., Hu, X. and Wang, X. (2017). Sub-Pixel Mapping Based on MAP Model and Spatial Attraction Theory for Remotely Sensed Image. IEEE Access, 5, 25126-25132. https://doi.org/10. 1109/ACCESS.2017.2768543

Wu, K., Wei, L., Wang, X., and Niu, R. (2016). Adaptive pixel unmixing based on a fuzzy ARTMAP neural network with selective endmembers. Soft Computing, 20. 4723. https://doi.org/10.1007/ s00500-015-1700-y

Yahiaoui, R., Alilat, F. and Loumi, S. (2017). Parallelization of Fuzzy ARTMAP Architecture on FPGA: Multispectral Classification of ALSAT-2A Images, IEEE Transactions on Industrial Electronics, 64 (12), 9487-9495. https://doi.org/10.1109/TIE.2017.2708028

Yanbin, Y., Xianxiao, X., Yunjun, Z., Xiao, L., Fan, Z. and Xiaopan, Z. (2010, April). The Application of Improved Fuzzy ARTMAP Neural Network in Remote Sensing Classification of Land use. In 2010 Second International Conference on Multimedia and Information Technology, 2, 35-38. https://doi.org/10.1109/M MIT.2010.28

Zagajewski, B. (2010). Classification of high-mountain plant communities using artificial neural nets and hyperspectral data. 2nd Workshop on Hyperspectral Image and Signal Processing. Evolution in Remote Sensing, Reykjavik, 1-4. https://doi.org/10.1109/ WHISPERS.2010.5594849 